\title{
A Low Cost Measurement System to Extract Kinematic Parameters from Walker Devices
}

\author{
J.M. Dias Pereira ${ }^{(1,2)}$, Octavian Postolache ${ }^{(2,3)}$ \\ (1) LabIM ESTSetúbal/IPS, Setúbal, Portugal \\ (2) Instituto de Telecomunicações, Lisbon, Portugal \\ (3) ISCTE-IUL, Lisbon, Portugal
}

\author{
Vítor Viegas $^{(1,2)}$, Pedro Silva Girão ${ }^{(2,4)}$ \\ (1) LabIM ESTSetúbal/IPS, Setúbal, Portugal \\ (2) Instituto de Telecomunicações, Lisbon, Portugal \\ (4) DEEC/Instituto Superior Técnico, Lisbon, Portugal
}

\begin{abstract}
This paper presents a low cost measurement system that can be used to extract kinematic parameters from walker devices. The proposed measurement system can be easily integrated in any commercial non-smart walker device and includes mainly a set of six force sensing resistors and one 3D accelerometer, with the associated signal conditioning circuits, and the data acquisition and processing unit with wireless communication capabilities. The signals that are acquired from the sensors are used to obtain, in real time, the values of several variables related with strength, acceleration and tilt angles that are associated with the usage of walker devices. The proposed measurement system enables the detection of conditions that are related with a deficient usage of the walker device, such as, bad positioning of the walker legs during gait, amplitude and timing unbalances of the forces applied on the walker legs or on the walker hand grips, excessive values of mechanical oscillations or tilt angles of the walker device. Some calibration and experimental results are included in the paper.
\end{abstract}

Keywords-force measurements; kinematic parameters; gait parameters; centroid; walker devices

\section{INTRODUCTION}

One of the main problems of today and future society is related with the quality of life of elderly people and obviously with their mobility. The aging of the population in the top developed countries is progressively increasing. For instance, statistical key numbers in European Union (EU-27), for year 2060, foresees that almost $30 \%$ of the population is aged over 65 and a life expectance of 89 and 84.5 years for women and men, respectively, is forecasted [1]. In this context, mobility of elderly people must be preserved as long as possible and motion aids are a real concern not only in terms of improving quality of life but also in terms of cost savings of health and long-term care systems [2-3]. In this context, it is important to refer that a large number of people that use mobility aiding devices, sometimes, don't use them properly. Bad use can generate unbalance and instability conditions and result in falls and harmful injuries [4-5]. The importance of this topic is also enlarged because an increasing number elderly people prefer to remain in their homes as long as possible. Thus, assistive technologies that include the usage of mobility aids, such as, canes, crutches, walkers, rollators, among others, demand an increasing attention namely in which concerns the research of reliable measurement systems that provide telemonitoring, telehealth and others technology-enabled services [6]. In this research area, issues related with reliability, self-control and power supply minimization of smart measurement solutions for mobility aiding devices [7-8] are of paramount importance. It is essential to promote the development of measurement solutions that can be integrated in non-smart walker devices to improve their capabilities at a low cost. In this context, this paper presents a technical solution that can be applied to walker devices in order to capture motion and force quantities from which several gait and posture parameters can be extracted. As main novelties and improvements that are associated with the proposed solution, behind its low cost and adaptability to existing walker devices, it must be underlined its reliability, its local and remote operating modes, its self-calibration capability and its capability to detect, in real time, potential falls conditions that are directly signalized to the walker user. To validate theoretical expectations, a prototype, based on a conventional walker with four legs ground contact configuration, was implemented and used for testing purposes. It is important to refer that the measurement principles and technical solutions that are presented can be applied to others mobility aiding devices such as canes, crutches and walkers with different ground contact configurations, namely with different type of combinations between legs and wheels.

This paper is organized as follows. Section two presents the theoretical basis of the measurement principle, section three is dedicated to system description, namely in which concerns its main hardware and software parts, section four presents some calibration and experimental results, and section five is dedicated to conclusions and future work.

\section{THEORETICAL BASIS}

The measurement principle used to measure the unbalance degree of the forces applied by the walker user on the mobility device is based on the evaluation of the centroid coordinates of the forces that are applied on the walker legs and on the walker hand grips. Considering, as an example, that Fig. 1 represents the set of six forces that are applied on the force sensing resistors (FSR), the centroid coordinates of the set of the forces that are applied on walker legs is given by: 
that the analysis of amplitude and timing unbalances of the forces applied, on the walker legs and walker hand grips, together with acceleration data, enables de access of a set of kinematic parameters that are surely important for gait rehabilitation assessment and to prevent potential injuries of elderly people that use walker devices to improve their mobility.

Concerning future work, it will include the development of additional software modules and the usage of pattern identification and data mining techniques to identify and characterize the gait parameters that are associated with the different gait disabilities in order to improve the capabilities of the proposed measurement system. Concerning the hardware component, future improvements could be related with the replacement of the acceleration unit by an inertial motion unit (IMU) [23-24] in order to evaluate additional kinematic parameters but a preliminary study, based on field measurement data, is required to analyze the real need of this improvement.

\section{ACKNOWLEDGMENTS}

The work was supported by Fundação para a Ciência e Tecnologia project PTDC/DTP-DES/1661/2012.

\section{References}

[1] European Commission, "Summaries of EU Legislation", Available at http://europa.eu/legislation_summaries/employment_and_social_policy/situa tion_in_europe/c10160_en.htm [accessed Sept. 2014].

[2] Sara M. Bradley, Cameron R. Hernandez, " Geriatric Assistive Devices", Am Fam Physician Issue 15, No. 84(4), pp. 405-411, 2011.

[3] S.R.Faruqui, T. Jaeblon," Ambulatory assistive devices in orthopaedics: uses and modifications", J Am Acad Orthop Surg. Issue 18, No. 1, p.p. 4150, 2010.

[4] H. Bateni, B.E. Maki, "Assistive devices for balance and mobility: benefits, demands, and adverse consequences", Arch Phys Med Rehabil, Issue 86, No. 1, pp. 134-145, 2005.

[5] J.A. Stevens, K. Thomas, L. Teh, Greenspan et al, "Unintentional fall injuries associated with walkers and canes in older adults treated in U.S. emergency departments", J Am Geriatr Soc. Issue 57, No. 8, pp. 1464-1469, 2009

[6] NTT data, Global IT Innovator, "Trends in Telehealth", Available at http://americas.nttdata.com/Industries/Industries/Healthcare/ /media/Docum ents/White-Papers/Trends-in-Telehealth-White-Paper.pdf [accessed Sept. 2014].

[7] O. Postolache, P.S. Girão, Eduardo Pinheiro, J.M. Dias Pereira, R Madeira, G. Postolache, J.M. Joaquim; "Multi-usage of Microwave Doppler Radar in Pervasive Healthcare Systems for Elderly ", Proc IEEE International Instrumentation and Technology Conf. - I2MTC, Vol. 1, pp. 30-34, Hangzhou, China, May 2011.

[8] Octavian Postolache, Vítor Viegas, J.M. Dias Pereira, D. Vinhas, Pedro Girão, G. Postolache, "Toward Developing a Smart Wheelchair for User Physiological Stress and Physical Activity Monitoring", 9th edition of IEEE International Symposium on Medical Measurement and Applications (MeMeA'14), Lisboa, Portugal, June 2014.

[9] Advanced Antivibration Components, Available at: http://www.vibrationmounts.com/Products6.html [accessed Sept. 2014].

[10] Interlink Electronics, "Force Sensing Resistors: integration guide and evaluation parts catalog", Available at: http://www.interlinkelectronics.com [accessed Sept. 2014].
[11] Analog Devices, iMEMS Accelerometer ADXL330, Available at: http://www.datasheetarchive.com/ADXL330KCPZ-datasheet.html [accessed Sept. 2014]

[12] Analog Devices, ADG1414 octal SPST w, Available at: http://www.analog.com/en/switchesmultiplexers/analog switches/adg1414/products/product.html [accessed Sept. 2014]

[13] Dallas Semiconductor, DS1804 NV trimmer potentiometer, Available at: http://pdf1.alldatasheet.com/datasheetpdf/view/58536/DALLAS/DS1804.html [accessed Sept. 2014].

[14] China Young Sun LED Technology Co., LTD, RGB triple color LED white diffused lens, model number YSL-R596CR3G4B5W-F12, Available at: http://inmotion.pt/documentation/sparkfun/COM-09264/YSLR596CR4G3B5W-F12.pdf [accessed Sept. 2014].

[15] Microchip Technology Inc., PIC16F87X Microcontroller, Available at: http://www.microchip.com html [accessed Sept. 2014].

[16] MDFLY Electronics, Wireless Bluetooth TTL Transceiver Module, Available at: http:// www.mdfly.com [accessed Sept. 2014].

[17] J.M. Dias Pereira, Vítor Viegas, Octavian Postolache, Pedro Silva Girão, "A Smart and Distributed Measurement System to Acquire and Analyze Mechanical Motion Parameters", Metrology and Measurement Systems, Vol. 20, No. 3, pp. 465-478, 2013.

[18] Peter Reen, " Implementing File I/O Functions Using Microchip's Memory Disk Drive File System Library", AN1045, Microchip, Available at: $\quad$ http://ww1.microchip.com/downloads/en/AppNotes/01045a.pdf [accessed Sept. 2014].

[19] AMETEK, "Portable Pneumatic Tester - model T730", Available at AMETEK, "Portable Pneumatic Tester [accessed Sept. 2014].

[20] Mettler-Toledo Gmbh, "Mettler Toledo Spider 1S Scales", Switzerland, 1999.

[21] Stanford Medicine 25, "Gait Abnormalities", Stanford School of Medicine, Available at: http://stanfordmedicine25.stanford.edu/the25/gait.html [accessed Sept. 2014].

[22] M.D. Van Hook, P. Demonbreun, M.D. Weiss, "Ambulatory Devices for Chronic Gait Disorders in the Elderly", Am Fam Physician, Vol. (8), 2003

[23] Sparkfun, IMU Digital Combo Board - 6 Degrees of Freedom Available http://www.sparkfun.com/products/10121 [accessed Sept. 2014]

[24] Juan C. Alvarez, R.C. Gonzável, Diego Alvarez, et al., "Multisensor Approach to Walking Distance Estimation with Foot Inertial Sensing", Proc. of the 29th Annual International Conference of IEEE EMBS, Vol. 1, pp. 5719-5722, 2007 